\title{
A 50 años del Cordobazo... Pensar las "puebladas" en la Argentina de los años setenta
}

\author{
Ana Julia Ramirez \\ Facultad de Humanidades y Ciencias de la Educación-Universidad Nacional de La Plata, \\ Centro de Investigaciones SocioHistóricas-Instituto de Investigaciones en Humanidades y \\ Ciencias Sociales, Argentina
}

\section{Resumen:}

El trabajo se propone revisitar el proceso político argentino de los tempranos años setenta a la luz de un análisis renovado sobre los estallidos populares mejor conocidos como puebladas o "azos", que imprimieron con tintes insurreccionales las protestas y movilizaciones del período y nutrieron de gran dinamismo e incertidumbre al proceso nacional.

Palabras Clave: Puebladas, Protesta social, Radicalización política.

\section{Abstract:}

50 year after that great popular uprising, known as "the Cordobazo", this article proposes to re-visit the argentine political process of the early seventies throght the ligh of a renewed approach to those episodes of collective action that colored with insurrectional overtones the cycle of protest and popular movilization that characterized the period and filled with high levels of uncertainty the nacional process.

KEYWORDS: Puebladas, Social protest, Political radicalization.

A 50 años de aquel gran estallido popular conocido como "el Cordobazo" resulta interesante volver a revisitar y pensar el proceso político argentino de los años setenta a la luz de aquellos episodios de acción colectiva conocidos como "puebladas" o "azos" que imprimieron con tintes insurreccionales al ciclo de protestas y movilizaciones del período. Con esta idea en mente, en este artículo me propongo dos objetivos. Por una parte, avanzar algunas líneas interpretativas y herramientas conceptuales que nos ayuden a una mejor comprensión de estos episodios de protesta en su singularidad, para luego, a partir de allí, repensar estos estallidos en su conjunto como "acontecimientos disruptivos" que nutrieron de gran dinamismo e incertidumbre al proceso político nacional.

Coincidimos con Cristina Tortti cuando señala que la historia de los sesenta y setenta debe pensarse como una etapa de contestación generalizada donde "lo novedoso radicaba en que, tanto en la sociedad como en la política, un clima de malestar creciente tendía a cuestionar el ordenamiento habitual de la vida social y las formas tradicionales de ejercicio de la autoridad y de la representación" (Tortti, 1999). En consecuencia, tomamos distancia de un campo historiográfico predominantemente orientado por lo que Omar Acha llama "violentología": una forma de pensar los setenta desde una matriz profundamente reduccionista que hace de la lucha armada y, en consecuencia, de la violencia política, el eje central y explicativo alrededor del cual analizar el proceso político argentino de aquellos años (Acha, 2010)

Desde estas premisas, creemos que el estudio pormenorizado y sistemático de este tipo de acontecimientos permite no sólo llenar de contenido más preciso ese "malestar" creciente en la sociedad sino también observar hasta qué punto estos estallidos en sí mismos expresaron formas de crítica sustantiva del orden político y social. A partir de ello, esperamos aportar también mayor densidad conceptual a la comprensión del proceso de formación de un campo de oposición política a la dictadura de la Revolución Argentina incorporando 
experiencias relativamente marginadas del análisis histórico dominante y que permiten dar cuenta de la diversidad de situaciones, expectativas y horizontes de sentido entrelazados y superpuestos que lo nutrieron.

\section{BREVE ESTADO DE LA CUESTIÓN}

A pesar de que en términos generales han sido las organizaciones armadas revolucionarias y la presencia perdurable de figuras e identidades políticas tradicionales (particularmente de Perón y el peronismo) los territorios más visitados por la historiografía que analiza el período 1966-1973, dada la masividad y recurrencia de estos estallidos, no resulta exagerado afirmar también que todas las narrativas e interpretaciones generales que intentan dar cuenta de este período de la historia argentina reconocen a las puebladas o "azos" como acontecimientos más que relevantes que le dieron un nuevo tono y rumbo al proceso político a partir de 1969, con el Cordobazo como hito fundamental. Por ello, en relación con los estudios específicos de lo que llamamos "puebladas" o "azos", es sin duda el caso del Cordobazo el que ha sido más profusamente analizado y el que ha generado más debates y discusiones (Tosco 1988, Delich 1974, Balvé 1973, Balvé y Balvé 1989, Flores 1994, Altamirano et al 1994, Brennan 1996, Gordillo 1996, Torre 1989 y 1994, Tarcus 1999, Hernandez 2000, Cena 2000, Pittaluga 2015, por citar a los más destacados). El resto de las puebladas de este período también ha concitado el interés de diversos investigadores que han escrito sobre esas experiencias, intentando en los últimos años recuperar algunas de ellas del relativo olvido social e historiográfico en que habían quedado. En particular debemos destacar las investigaciones sobre los tucumanazos (Crenzel 1991, Kotler 2000, Ramírez 2008, Nassif 2012), sobre los rosariazos (Antognazi y Ferrer 1995, Pérez y Viano 1994) sobre la Asamblea del Pueblo de Trelew (Eloy Martinez 1997, Western, Fernández Pícolo y De Oto 1991, Ramírez 2007, Arrutti 2004, Bassi y Pauli, 2003), sobre el mendozazo (Scodeller 2006, Colectivo Fantomas 2012) sobre el catamarqueñazo (Alvarez 2006), sobre el rocazo (Favaro, Zapata, Araya 2010, Ramirez 2001, Bohovslavsky y Yappert 2012), sobre el gallegazo (Auzoberría 2007), sobre el jujeñazo (Castillo 2007) y sobre las puebladas de Cipolletti y Casilda (Balvé y Aufgang 1989). Sin embargo, salvo por Balvé (1986) y Ramírez (2008) han sido muy pocos los intentos por pensar estos estallidos en su conjunto y dentro de un marco conceptual que permita su comprensión e interpretación más general, en tanto forma recurrente y novedosa que tomó la intervención política de amplios sectores sociales en diversas localidades del interior del país durante aquellos años.

Tratando de recuperar las perspectivas más generales desde las cuales, explícita o implícitamente, se han abordado estos estallidos de protesta, encontramos por un lado que aquellos autores que analizan la política del período desde una perspectiva más bien institucionalista y que ponen el acento en las normas de funcionamiento del sistema político, suelen ver en estos estallidos la expresión espontánea y casi "natural" de una sociedad civil enajenada por el autoritarismo de la dictadura de la Revolución Argentina y la demanda por recuperar cierta habitualidad política considerada centralmente como vuelta al constitucionalismo y al gobierno representativo (Hilb \& Lutzky 1986, Ollier 1986, Halperín 1994, De Riz 2000, Romero 2000). Desde esta mirada, acontecimientos como las puebladas u otras movilizaciones masivas de envergadura aparecen como el telón de fondo de la política; como un efecto del mal funcionamiento del sistema político por donde se colaban los malestares y demandas que en otro contexto se habrían canalizado naturalmente por medio de los mecanismos representativos y tradicionales del sistema político. En consecuencia, en tanto que efectos secundarios de un problema político cuyas causas están en otra parte, esta perspectiva no se ha ocupado del estudio de estos episodios como objetos de investigación por derecho propio.

Otros autores, más consustanciados con una visión de la política como dimensión expresiva del conflicto social, suelen ver en estos episodios el grado de desarrollo alcanzado por la lucha de clases en nuestro país (Balvé y Balvé 1973, Balvé y Aufgang 1989, Crenzel 1991, Antognazi y Ferrer 1995, Bonavena 1999, Kotler 2006, Scodeller 2006, Auzoberría 2007, Nassif 2012). Desde esta perspectiva, mucho más atenta a las diversas formas de la política y de la organización y acción popular que a la lógica de funcionamiento 
institucional, los estallidos como los aquí analizados estarían dando cuenta, más bien, del nivel de conciencia alcanzado por los sectores populares, en particular la clase obrera. En consecuencia, para estos autores, el estudio de este tipo de episodios adquiere una dimensión central. A partir de ello, esta línea de análisis ha asumido el desafío y la necesidad de investigar la diversidad y heterogeneidad de situaciones que sin mayores especificaciones se identifican como "puebladas" o "azos" con el objetivo de precisar mejor su naturaleza, actores y sentidos y producir una interpretación general. En esta dirección, ya temprano en 1989, Beba Balvé introdujo la distinción analítica entre "puebladas" por un lado y “azos" por el otro, que, con matices, perdura hasta hoy como eje articulador de varios análisis y estudios de caso (Balvé y Augang 1989, Crenzel 1991, Antognazi y Ferrer 1995, Scodeller 2006, Álvarez 2006, Bohovslavsky y Yappert 2012, Favaro, Zapata, Araya 2011, Nasiff 2012). En esta tipología las “puebladas" serían aquellas insurrecciones en las que se expresó el interés corporativo de una ciudad evidenciado en el rol protagónico que tuvieron en el conflicto sectores de las elites locales, y donde los sectores subalternos simplemente se sumaron y acompañaron la disputa sin mayor autonomía ni demandas propias. Casos como los de Cipolletti y General Roca serían ejemplo de esta categoría. Por el contrario, los "azos" serían aquellos episodios en los que el tipo de demandas y el rol dirigente que durante las protestas tuvieron los sectores subalternos, especialmente los obreros, estarían dando cuenta del grado de evolución alcanzado por la lucha de clases. En esta dirección, por ejemplo, las tensiones y conflictos que se expresaron en el Cordobazo y el Rosariazo de 1969 y se continuaron en el Viborazo de 1971 o se expresaron en los "Tucumanazos" (por nombrar sólo a algunos casos), donde confluyeron la "lucha de calles" con la participación protagónica de sectores obreros y estudiantiles radicalizados, estarían dando cuenta de la convergencia "del conjunto del pueblo" en torno a la clase obrera y los movimientos revolucionarios (Balve 1989, Crenzel 1991, Berrotarán y Pozzi, 1995, Bonavena et al, 1999).

En estas dos formas de pensar estos estallidos, el pueblo se interpreta o bien como una referencia abstracta que hace alusión a la teoría de la representación ciudadana o bien como expresión sociológica y empírica de una presupuesta conciencia de clase.

\section{Algunos Casos menos conocidos}

¿De qué tipo de protestas estamos hablando? Si bien todavía no contamos con una definición precisa ni con un conteo exhaustivo de casos, siguiendo a la bibliografía más especializada podemos dar cuenta de al menos 19 episodios denominados "azos" o "puebladas" que ocurrieron en distintas ciudades del interior de la Argentina entre 1969 y $1972^{1}$. En términos generales podemos decir que durante estos episodios miles de personas salieron a las calles de su ciudad con la intención de desafiar colectivamente alguna o varias medidas tomadas por la autoridad provincial o nacional que los afectaba. Estas protestas, fueron variadas en su duración, implicaron la movilización masiva de diversos actores políticos y sectores sociales y la expansión de las redes de interacción colectiva en el ámbito local, en la medida que los diversos actores movilizados confluían en las calles y desafiaban el control del espacio urbano. En algunos casos, estas acciones produjeron enfrentamientos muy violentos con las fuerzas de seguridad, el levantamiento de barricadas y la destrucción de símbolos del poder público y privado, mientras que en otros casos la violencia se mantuvo como una amenaza latente. En algunos casos, los manifestantes llegaron a establecer "comunas" o "gobiernos provisorios", mientras duró la protesta. En todos los casos, en consecuencia, estas protestas produjeron fuertes alteraciones en la dinámica de la vida cotidiana y desafiaron las normas que articulaban las relaciones sociales y políticas en estas localidades. Asimismo, en la mayoría de los casos, estas protestas forzaron la satisfacción de muchas de las demandas planteadas y cambios en la composición de las autoridades locales, provinciales y hasta, en algunos casos, nacionales ${ }^{2}$. Finalmente, estas protestas tuvieron como característica particular y distintiva la movilización multisectorial y que sus protagonistas legitimaron y llevaron adelante sus acciones en nombre de los intereses y derechos "del pueblo". 
A modo de ejemplo, a continuación, sintetizaré algunos casos previamente trabajados en mis propias investigaciones con la intensión de mostrar la diversidad de situaciones de las que estamos hablando.

\section{El Quintazo (Tucumán 1972)}

El estallido llamado "segundo Tucumanazo" o "Quintazo", ocurrido en la ciudad de San Miguel de Tucumán en junio de 1972, nos retrotrae a la situación de una provincia particularmente convulsionada desde los planes de reconversión productiva puestos en marcha hacia 1966 y que tiene como antecedentes diversos momentos de altísima conflictividad política y social en 1969 y en 1970 . Dentro de esta trama de más largo plazo, el estallido de 1972 nos remite para su estudio en particular, a una compleja y dinámica superposición de actores y conflictos que abarcaban desde los planes de lucha de los estudiantes radicalizados y las juventudes partidarias contra la Revolución Argentina hasta las demandas contra el aumento del costo de vida encabezadas por diversas asociaciones vecinales, pasando por la oposición de la UNT a la privatización de un yacimiento de cobre en Catamarca, los reclamos de abogados y familiares de presos políticos contra la legislación represiva, las demandas salariales de los gremios de empleados estatales, en particular de los docentes, los empleados de la administración pública provincial y municipal y de los empleados judiciales, e incluso al profundo malestar de la Corte suprema de Justicia provincial respecto a su falta de autonomía para resolver los problemas gremiales de la justicia local.

Estos conflictos venían activando desde semanas antes al estallido acciones colectivas a partir de las cuales, las organizaciones implicadas fueron construyendo puentes con el fin explícito de crear un movimiento de oposición provincial contra la dictadura. Este clima de activación y movilización creciente implicó desde el desconocimiento de la Corte Suprema de la Provincia a la autoridad jurídica del gobierno de la Revolución Argentina hasta múltiples manifestaciones y huelgas sectoriales que paralizaron la educación, la administración pública y la justicia provincial durante los días previos. En este contexto fuertemente enrarecido, los violentos enfrentamientos que se desataron entre el 21 y el 27 de junio, conocidos como "El Quintazo", se iniciaron a raíz de la represión desatada contra una manifestación de empleados estatales que luego de realizar una asamblea frente a la casa de gobierno, marchó hacia las inmediaciones de la Quinta Agronómica para confluir con los estudiantes universitarios. Ante ello, los manifestantes se recluyeron en el comedor universitario que comenzó a ser también fuertemente reprimido. A partir de allí, la zona céntrica de la ciudad -donde estaban radicadas varias Facultades de la UNT, y la zona circundante a la Quinta Agronómica -donde estaba radicado el comedor universitario- se convirtieron en un campo de batalla en el que estudiantes universitarios y pobladores del barrio Ciudadela (la barriada lindante a la Quinta Agronómica) resistieron por 6 días la presencia de las fuerzas de seguridad en estas áreas de ejido urbano, mientras ocurrían simultáneamente actos relámpago y manifestaciones sectoriales en el resto de la ciudad.

La violencia durante estos días fue increscendo, en la medida que a las fuerzas de la policía provincial se fueron sumando, los días 23 y 24, regimientos de Gendarmería y del Ejército provenientes de la provincia de Salta, pero sobre todo a partir de la tarde del 24, cuando la represión se cobró la vida de un estudiante y obrero metalúrgico, Héctor Villaba, alcanzado por una granada mientras escapaba por lo techos de las casas del barrio Ciudadela.

Este dramático acontecimiento paralizó los enfrentamientos sólo por un rato, que el gobernador aprovechó para emitir un mensaje televisado dirigido a la comunidad -definido como "patético" por el diario local La Gaceta. En el mismo, luego de remarcar varias veces su amor a las instituciones y a la democracia -considerada por el gobernador "biológica" en nuestro país- y de llamar a la calma y a la reflexión a toda la población, el gobernador anunció la separación del Jefe de Policía, un asueto en todos los niveles de la educación por una semana y el cierre de las fronteras provinciales "para evitar hechos mayores". Para ese entonces, la muerte de Villalba había comenzado a producir manifestaciones estudiantiles de repudio en otras ciudades del país. Asimismo, mientras el gobernador hablaba por televisión, se realizaba en la Facultad de 
Derecho, tomada por los estudiantes desde el día 21, una conferencia de prensa convocada por un grupo de abogados para denunciar los apremios ilegales a los que eran sometidos activistas y estudiantes detenidos en la provincia por presunta vinculación con hechos extremistas. ${ }^{3}$

Durante la noche del 24 los estudiantes convocaron a una asamblea en la Quinta Agronómica, de la cual participaron también algunos trabajadores no docentes de la UNT, grupos de ex-obreros de ingenios cerrados, vecinos del barrio Cuidadela, los médicos y enfermeros que tuvieron contacto con el cuerpo del estudiante asesinado y el rector del Universidad, quien luego de solidarizarse con los estudiantes por muerte de Villalba expresó "su preocupación profunda porque la universidad esté siendo utilizada” y exhortó a los estudiantes a dejar las barricadas. ${ }^{4} L o s$ estudiantes rechazaron la propuesta del rector planteando que "la única manera de responder a la dictadura es a través de la lucha del pueblo" y lo invitaron, al contrario, a quedarse con ellos en las barricadas. ${ }^{5}$

La asamblea también decidió organizar una misa popular durante la mañana del día 25 , en honor al compañero asesinado. La misa fue presidida por dos reconocidos curas tercermundistas y convocó a una multitud de estudiantes que después del oficio iniciaron una movilización por el barrio durante el transcurso de la cual, según las crónicas del diario local, se volvieron a levantar barricadas, se destruyó el alumbrado público, se escucharon vivas a Perón, Montoneros, el ERP y las FAR y se reiniciaron los enfrentamientos con las fuerzas de seguridad. ${ }^{6}$

Por su parte, ese mismo día 25 de junio la CGT local anunció un paro general de actividades para el martes 27, declarado "Día de Duelo para Tucumán", en repudio a la "represión indiscriminada por parte de la policía, las fuerzas militares y el gobierno contra la población”, en solidaridad con los gremios en conflicto, contra el aumento de las tarifas de los servicios público, "contra la privatización del yacimiento Farallón Negro y su exploración y explotación por parte del Estado”, por la libertad de los presos gremiales, políticos y estudiantiles, por la libertad de prensa y contra el aumento del costo de vida. ${ }^{7}$ Manifestaron de inmediato su adhesión al paro general casi todos los gremios locales afiliados a la central sindical, entre ellos la FOTIA, las 62 Organizaciones y la Intergremial de Ingenios Cerrados. ${ }^{8}$ A partir de la muerte del estudiante Villalba también comenzaron a pronunciarse contra la represión los partidos políticos y diversas asociaciones empresariales y de la sociedad civil. La Federación Económica de Tucumán, por ejemplo, llamó públicamente a la reflexión y a la pacificación de todos los sectores tucumanos, y algunos de sus dirigentes viajaron a Buenos Aires para entrevistarse con el Ministro del Interior de la Nación con la intención de "aportar a la resolución del conflicto".?

Fue recién a partir de dos impresionantes operativos realizados entre la noche del 26 y la madrugada del 27 de junio que las fuerzas del orden recobraron el control de la ciudad. La cantidad total de detenidos a lo largo de los 6 días que duraron los enfrentamientos sumó alrededor de 400; de los cuales más de la mitad fueron arrestados entre el 25 y la mañana del 27, días que también dejaron un alto saldo de heridos. ${ }^{10}$ Es difícil precisar el número total de participantes a lo largo de estos días de furia. De hecho, las referencias cuantitativas son escasas en las crónicas consultadas. No obstante, mientras algunos medios hablaron de un total de cerca de 4000 estudiantes y pobladores participando de los enfrentamientos del día 25, y un informe de la Secretaría de Inteligencia del Estado con fecha 26 de junio menciona de alrededor de 1000 estudiantes resistiendo en la zona céntrica y de otros 1500 en la zona de la Quinta Agronómica ${ }^{11}$

Como corolario de este estallido, el gobierno nacional aportó los fondos necesarios para que la provincial pudiera cumplir con el pago de los sueldos y aguinaldos atrasados y con los aumentos que se acordaron para los distintos sectores de la administración pública provincial. En el terreno universitario más amplio, el rector renunció como expresión de repudio a la represión desatada contra los estudiantes, pero también el gobierno nacional desistió de sus acciones en favor de la privatización del yacimiento Farallón Negro perteneciente a la UNT y a la que se oponía la comunidad universitaria en su conjunto. 


\section{El Rocazo (Julio 1972)}

La pueblada conocida como el "Rocazo" ocurrió en la ciudad de General Roca, provincia de Río Negro, entre el 4 y el 20 de julio de 1972. Si bien en el Rocazo estuvieron involucrados la mayoría de los habitantes de la ciudad, sobresale la participación que tuvieron la elite política, empresarial y profesional de la ciudad, la JP regional y las asociaciones vecinales de los barrios pobres. Fueron la Cámara de Industria Agricultura y Comercio, el Colegio de Abogados y los dirigentes políticos de la UCR quienes, en gran medida, dirigieron e impusieron un tono particular a esta protesta. La chispa que disparó la movilización fue la decisión del gobernador -Vicente Requeijo- de crear nuevos juzgados en la pujante ciudad vecina de Cipolletti a cambio de su apoyo electoral en las próximas elecciones. Esto sucedía en el marco de una fuerte competencia entre General Roca y Cipolletti por la hegemonía regional. Esta puja ya había producido una primera pueblada en la región en 1969, el Cipolletazo, vinculada al inicio de las obras del Chocón. ${ }^{12}$ Desde entonces General Roca se había convertido en el principal bastión opositor a las políticas oficiales para la región. En consecuencia, más que dar cuenta de la agudización del conflicto social en esta localidad o de la emergencia de un movimiento antimilitar, el Rocazo nos habla, sobre todo, de la superposición de la lucha de una elite local por mantener su preeminencia económica y política en la región, con el enfrentamiento estratégico de las fuerzas partidarias en el contexto de la incipiente disputa electoral.

Por supuesto, que estos conflictos hayan estimulado un nivel de participación tal que permitieron a la ciudad mantenerse en estado de rebeldía contra las autoridades provinciales durante casi 15 días, se explica por su articulación con las demandas de otros sectores, también en la oposición al gobierno de Requeijo. La demanda de alejamiento del gobernador, en consecuencia, logró articular una pluralidad de intereses y de actores que probablemente en otro contexto no habrían convergido tan fácilmente, y que incluían sin duda el repudio de muchos al autoritarismo militar e incluso la convicción de que por esta vía se estaba avanzando en la lucha contra el sistema. Sin embargo, mirada desde el punto de vista social o ideológico predominante, esta protesta expresaba objetivos más bien conservadores: la lucha de una elite local por defender su hegemonía regional amenazada.

A pesar de ello, este caso sorprende por sus acciones. Aparte de tomar la municipalidad, destituir al intendente y enfrentarse con la policía y las fuerzas militares en las calles, los vecinos de Roca, reunidos en asamblea, crearon una Comisión Provisoria de Gobierno (CPG) con representantes de todas las asociaciones de la sociedad civil para ocupar el lugar vacío del poder municipal. También decidieron no pagar los impuestos provinciales, retirar los depósitos del banco de la Provincia, dar asistencia médica y jurídica gratuita a todos los afectados por la represión y revertir el sentido de las calles hasta tanto renunciara el gobernador. Como los medios de comunicación local fueron intervenidos por unos días, también crearon una radio clandestina para informar sobre las medidas tomadas por la CPG y convocar a la población, por ejemplo, a un acto de celebración de la Independencia Nacional alternativo al acto oficial organizado por las autoridades militares a cargo de la provincia -acto en el que los roquenses le dieron la espalda a los uniformados y un grupo de jóvenes arrió la bandera previamente izada por los militares para volver a izarla "pero ahora por deseo del pueblo". ${ }^{13}$

Estas acciones podían servir a diversos fines: a los abogados de Roca para seguir controlando la justicia en la región del Alto Valle; a los empresarios locales para resistir la competencia de la más concentrada y transnacionalizada producción frutícola de Cipolletti; a los dirigentes de la UCR para resistir la competencia de un nuevo partido provincial y reposicionarse en la disputa electoral. Para todos ellos, este movimiento fue un modo de resistir la pérdida de una hegemonía históricamente arraigada a la ciudad de General Roca. También podían servirle a la JP local para disputar su lugar dentro de la estructura partidaria del PJ provincial, para confrontar a una dirigencia gremial profundamente consustanciada con la CGT oficial, o para dar cuenta de su expandido alcance territorial. Pero más allá de las motivaciones estratégicas de las dirigencias de los distintos sectores involucrados, los cierto es que, a lo largo de casi 15 días, la mayoría de los habitantes de esta ciudad se encontraron en las calles enfrentando a la policía y a los militares, participando de manera 
igualitaria en el efímero gobierno provisorio e igualmente sometidos a la represión militar y a la justicia del Fuero Federal Antisubversivo.

Esta aparente comunión, sin embargo, duró poco. Cuando en la noche del 9 de julio volvieron a encenderse fogatas en las calles y un incendio destruyó las oficinas de la Dirección General de Rentas de la Provincia comenzó a romperse la unidad. La CPG repudió el hecho como un "acto vandálico que no hace al respeto del derecho que nosotros mismos reclamamos", imputó la responsabilidad a "un grupo ajeno a nuestra comunidad" y remarcó la "cordura con que nuestra población se mantuvo hasta hoy". ${ }^{14}$ A partir de este hecho los notables comenzaron a retraerse de la acción callejera y optaron por el camino menos arriesgado, abierto por la propia protesta, de la negociación directa con las autoridades nacionales, aunque la CPG siguió funcionando hasta el día 18 cuando se anunció la renuncia del gobernador. Como corolario de este proceso no se crearon los juzgados en Cipolletti y, aunque el gobernador tuvo que renunciar a su cargo, no lo hizo a su candidatura. Su partido (el Partido Provincial Rionegrino) salió segundo a nivel provincial en las alecciones de 1973 detrás del Peronismo y lejos por delante de la UCR que, no obstante, logró un primer lugar en la ciudad de General Roca.

\section{El Trelewazo o "Asamblea del pueblo"}

En el caso del "Trelewazo" o "Asamblea del Pueblo" ocurrida en Trelew en octubre de 1972, el conflicto se sostuvo gracias a la participación masiva de los habitantes de las ciudades de Trelew y Rawson, mayoritariamente conformadas por sectores medios profesionales y empleados estatales, pero que también incluía a los sectores que habitaban los barrios populares de estas localidades. En esta ocasión, la insurrección se expandió luego de que tropas militares entraran subrepticiamente a la ciudad y requisaran violentamente cientos de domicilios en busca de "elementos subversivos", llevándose finalmente a 16 personas detenidas. Esto sucedió dos meses después que los líderes de las tres mayores organizaciones revolucionarias escaparan del penal de Rawson y el ejército fusilara a 16 guerrilleros presos en represalia ${ }^{15}$

La primera reacción al operativo militar provino de los dirigentes de los partidos políticos que se reunieron de inmediato en el local del MID y decidieron mandar telegramas conjuntos a las autoridades nacionales y provinciales, y a sus respectivos líderes a nivel nacional, repudiando el procedimiento militar y reclamando la libertad de los vecinos detenidos. ${ }^{16}$ Estos mismos dirigentes convocaron luego a una concentración popular a desarrollarse al mediodía en el recinto del teatro Municipal de Trelew (mejor conocido como Teatro Español) para acordar un curso de acción a seguir conjuntamente con otras organizaciones sociales y la población en general.

La convocatoria tuvo un éxito rotundo. Apenas horas más tarde se habían reunido en el Teatro Municipal alrededor de 500 personas representativas de los partidos políticos, de organizaciones de la sociedad civil y vecinos a título personal. ${ }^{17} \mathrm{El}$ meeting se autoproclamó "Asamblea del Pueblo" y se impuso como objetivo único la liberación de los 16 vecinos arrestados esa misma mañana y la del Dr. Mario Abel Amaya encarcelado desde mediados de agosto. ${ }^{18} \mathrm{~A}$ poco de comenzar las deliberaciones varios carteles que rezaban "Casa del Pueblo", "aquí sesiona el pueblo", y "libertad a los presos de la solidaridad" se integraron a una escenografía al principio solo presidida por una mesa de dirigentes políticos locales. Como contracara del gran número de organizaciones que participaron activamente o adscribieron al llamamiento existieron, sin embargo, ausencias de peso: la de la CGT local, sospechada de haber denunciado a varios de los detenidos, y la de la Cámara de Industria y Comercio (CIC) del valle del Chubut (con sede en Trelew). A pesar de ello, gran parte de los comerciantes y una cantidad más que representativa de los sindicatos locales participaron activamente de las varias reuniones públicas organizadas por la Asamblea del Pueblo, de sus manifestaciones callejeras -5 manifestaciones que congregaron alrededor de 3.000 a 5.000 personas cada una, en una ciudad de apenas 
25.0000 habitantes, - y de las 2 huelgas generales que paralizaron la casi totalidad de la actividad pública y económica de Trelew, Rawson y Puerto Madryn en el plazo de 15 días.

El Trelewazo contiene muchos rasgos peculiares que no podemos analizar en este trabajo. No obstante, quiero profundizar uno de ellos: quiénes eran los 16 detenidos. La mayoría de ellos vivían en Trelew y Rawson y sólo uno residía en Puerto Madryn. Nueve de ellos eran profesionales reconocidos en la comunidad local (abogados, escribanos, médicos, periodistas, artistas, profesores, psicólogos), dos eran obreros industriales; otro era estudiante universitario, y otros tres eran empleados de la administración provincial. La mayoría de ellos eran miembros activos de la vida política local: seis eran militantes peronistas vinculados a los sectores renovadores dentro del partido, en particular a la JP; otros tres estaban enrolados en las filas de la UCR, particularmente en el Movimiento de Renovación y Cambio y en el ENA; uno era militante del PC, otro del MID y otro de PSP. A la vez, tres de los detenidos también eran referentes del nuevo sindicato de Obreros y Empleados de la Administración Pública de la provincia de Chubut (SOYEAP) que, en este momento, estaba a la cabeza de la lucha por un sindicalismo que se autodefinía como antiburocrático para la región. Otros dos de los detenidos también tenían participación activa en las organizaciones barriales que luchaban por mejoras urbanas, y otros dos eran referentes de una renovada actividad cultural desarrollada por grupos de teatro independiente fuertemente dirigida hacia los barrios populares de ambas ciudades

Finalmente, y sobre todo, la mayoría de los detenidos tenían participación en la Comisión de Solidaridad con los Presos Políticos (CSPP), creada en septiembre de 1971 como respuesta a la conversión de la Unidad 6 de Rawson en cárcel de extrema seguridad para presos considerados extremistas subversivos. ${ }^{19}$ Si bien la CSPP presentaba sus objetivos como una contribución al apoyo material y moral de los presos y sus familias, también era evidente la tarea política que cumplía: crear una conciencia solidaria con los militantes revolucionarios, una corriente de oposición a las políticas represivas y leyes de excepción del gobierno, y romper el aislamiento de los prisioneros. ${ }^{20}$

En definitiva, las 16 personas detenidas en octubre cubrían casi todo el espectro de actividades profesionales, políticas, culturales y asociativas de las ciudades de Trelew y Rawson y la mayoría confluían en la CSPP. Ello nos permite pensar en una sociedad local fuertemente cohesionada, en la cual las nuevas y viejas formas de la actividad política convivían más o menos cooperativamente.

Esta cohesionada comunidad local, sin embargo, no era homogénea ni estaba libre de conflictos, ni era la primera vez que tomaba las calles, formaba asambleas populares o experimentaba con formas horizontales de organización y deliberación. Lamentablemente no tenemos lugar aquí para reseñar la interesantísima protesta organizada por las fuerzas viva de Rawson hacia fines de marzo de 1972, definida como un "Rawsonazo" por la prensa local, en oposición a una política provincial que, según sus protagonistas, beneficiaba arbitrariamente a Trelew en detrimento de los intereses de la capital. Ni las acciones de las asociaciones vecinales surgidas en los barrios periféricos para resolver los problemas resultantes de un acelerado crecimiento poblacional huérfano de políticas de planificación urbana, en vinculación con la militancia política juvenil y las nuevas formas de intervención cultural. O los enfrentamientos suscitados entre los nuevos gremios de empleados públicos que se autodefinían como antiburocráticos y el gobierno provincial o la dirigencia tradicional de la CGT regional. $\mathrm{Ni}$ el intento fallido de algunos sectores por movilizar a la población en oposición al arresto del abogado local Mario Abel Amaya, producido el 18 de agosto, acusado de complicidad con la fuga de los guerrilleros de la U6 poco días antes. ${ }^{21}$ La incorporación de estos otros conflictos al análisis del Trelewazo es importante porque muestra cómo las redes sociales y políticas y las diversas formas de acción colectiva que sostuvieron este movimiento ya se venían activando y ensayando al calor de demandas sectoriales más específicas. Estos conflictos también muestran que los 16 arrestados en octubre representaban, de alguna manera, a todos estos sectores en conflicto. También desmienten, rotundamente, la idea tan generalizada de que hasta que llegaron los presos políticos esta era una región "donde nunca pasaba nada; sólo el viento". ${ }^{22}$ 


\section{EL PUEBLO}

Como se desprende de las sintéticas descripciones precedentes, podemos considerar que las "puebladas" ocurridas en estos años fueron resultado de procesos y conflictos fuertemente localizados (Gonzalez Bombal, 1988, Fradkin, 2001) con diferentes causas, composición social y trayectorias que, sin embargo, compartieron una forma y dinámica común de la cual emergió el "pueblo" como significante capaz de articular identidades y demandas heterogéneas con formas y sentidos novedosos de organización social y de intervención política (Laclau, 2005).

En los tres casos previamente reseñados, por otra parte, las demandas sectoriales específicas que habían catalizado el inicio de los conflictos se fueron subsumiendo en una crítica más general contra el régimen de la Revolución Argentina y en muchos casos también contra el sistema social en su conjunto, en la medida que la movilización se deslizaba hacia la rebelión y la propia dinámica de la acción colectiva delineaba los contornos de este colectivo, a la vez heterogéneo y convergente, que se configuraba en torno a la idea de un "pueblo" violentamente reprimido, injustamente avasallado o relegado de la toma de decisiones pero a la vez también concebido de distinto modo por los participantes. Mientras que para algunos de sus protagonistas el pueblo en estas protestas reactualizaba las nociones decimonónicas de virtud burguesa y republicana o el sentido federal de los pactos preexistentes, para otros significaba la continuación de 17 años de lucha y proscripción, un escalón en el proceso revolucionario o la vuelta a la institucionalidad democrática. Así, en los tres casos estudiados, nos encontramos con que el "pueblo" movilizado era uno y varios a la vez. Era el pueblo local o del interior, el pueblo trabajador y peronista, el pueblo liberal y democrático, el pueblo revolucionario y antiimperialista.

Esta forma de emergencia del "pueblo" en las puebladas o "azos" no parece factible de subsumirse fácilmente ni a la representación abstracta de la soberanía, ni a una particular expresión de la conciencia de clase. Es por ello que esta forma particular e imprecisa de la emergencia del pueblo en estos estallidos es un dato central que me interesa resaltar para pensar tanto la filiación entre acontecimientos con características locales de naturaleza diversa como sus vínculos con -y sus efectos sobre- el escenario nacional.

\section{OTRA PROPUESTA DE INTERPRETACIÓN}

Ya sea que la oposición masiva y beligerante contra la dictadura de la Revolución Argentina manifestada en estos episodios sea interpretada como expresión de la conciencia revolucionaria del pueblo identificado con la clase obrera y los movimientos revolucionarios, como el resultado de conflictos al interior de las elites locales, o bien como expresión de una difusa y naturalizada "ciudadanía" reclamando por el retorno a un régimen constitucional y representativo, en todos los casos los análisis parten de nociones preconcebidas y en general axiomáticas sobre el conflicto social y político y los sujetos que los encarnan, y fusionan o separan radicalmente las múltiples, sobreimpuestas y hasta a veces contradictorias luchas y sentidos que expresaron estas rebeliones. Como resultado de ello, surge una imagen parcial y simplificadora de esta acciones de protesta que termina reduciendo su interpretación a la identificación de los conflictos que las catalizaron y a los intereses "objetivos" y preexistentes de los sectores sociales que las protagonizaron, como si las protestas mismas y su particular forma de manifestación fueran el resultado "natural" de estos conflictos o subjetividades y no fuera necesaria su problematización en tanto que "estallidos", en tanto que "rebeliones" que irrumpieron en la escena y resignificaron con su propia dinámica los conflictos e identidades preexistentes que los habilitaron.

Identificar los agravios y a los sectores sociales que protagonizaron estos episodios es una cuestión central a la que toda investigación debe contribuir. Sin embargo, ello no alcanza para explicar estos estallidos ni para interpretar su significado ni su inscripción en el proceso político nacional por varias razones. Entre ellas, porque este tipo de enfoques deja sin respuesta muchos e importantes interrogantes que hacen al análisis 
y explicación de estas experiencias en tanto forma específica que tomó la acción colectiva de protesta en estas localidades: ¿Por qué conflictos y demandas que involucraron a actores con trayectorias, identidades e intereses tan diversos convergieron en esta forma particular de protesta? ¿Qué mecanismos específicos de movilización y repertorios de acción posibilitaron el deslizamiento de las protestas sectoriales hacia la rebelión colectiva y la emergencia del "pueblo" en cada caso? ¿Qué sentidos o configuraciones de "pueblo" articularon estos episodios? ¿Hasta dónde el "pueblo" que se configuró en estos acontecimientos implicó la resignificación de identidades preexistentes? ¿De qué modo particular y a través de qué mecanismos específicos estos pueblos insurrectos lograron articular los intereses corporativos con las demandas por el retorno a un sistema representativo y la lucha revolucionaria?

En definitiva, lo que estos enfoques impiden visualizar es cómo la diversidad de actores, luchas y sentidos diferenciales pero convergentes que concurrieron y posibilitaron estos acontecimientos se transformaron $y$ resignificaron al calor de la lucha misma; al calor de una dinámica de confrontación que en su propio devenir generaba desplazamientos imprevisibles, no prefigurados en sus causas, que corrían los límites posibles de la acción dando lugar a experiencias y sentidos que desbordaban los objetivos específicos y preexistentes de los distintos sectores movilizados.

Partiendo de estas preguntas y consideraciones, nuestra propuesta de interpretación implica desplazar el análisis de los actores y los conflictos hacia el análisis de la dinámica y las formas que tomó la acción colectiva contenciosa en el marco de un proceso político signado por la ampliación y radicalización de los horizontes de expectativas que imprimió a la política del período unos rasgos y características particulares no subsumibles o reductibles a la mera identificación de los actores, los conflictos y los objetivos que los movilizaron. En este sentido es posible recuperar como ejemplo, un problema que aparece con recurrencia en muchas de las interpretaciones sobre el Cordobazo, que como señalamos anteriormente, ha sido la pueblada o "azo" más estudiada y que ha generado mayores desarrollos interpretativos. Más allá de la riqueza empírica y analítica y de las diferentes interpretaciones y dimensiones del problema que analiza cada una de las obras dedicadas a estudiarlo, nos interesa resaltar tres cuestiones centrales que cruzan a la mayoría de estos análisis y que remiten al problema que intentamos pensar en este trabajo: 1) el Cordobazo, fue un estallido espontáneo o fue una acción colectiva organizada? 2) cuál era la composición social predominante y la identidad de los sujetos que protagonizaron el acontecimiento -básicamente si el Cordobazo fue mayoritariamente una protesta obrera o estudiantil, y si los obreros que participaron eran peronistas o revolucionarios y 3) cómo definir a esta protesta -fue un movimiento de "desobediencia civil", una "rebelión obrera", un "hecho revolucionario de masas", un "movimiento antiburocrático", un "movimiento aintiautoritario", una "revuelta urbana”, un "movimiento de oposición política” por nombrar sólo algunas definiciones. ${ }^{23}$ En relación a este último punto, por ejemplo, es muy sintomática la forma en que Brennan y Gordillo $(1996,2001)$ terminan definiendo al Cordobazo a la vez como "una protesta popular con carácter predominantemente obrero", pero también con elementos de "rebelión popular" y de "insurrección urbana".

Esta multiplicidad de formas de definir e interpretar al Cordobazo, su dinámica y la identidad de sus protagonistas surge de la diversidad de sentidos, prácticas y actores que confluyeron y se manifestaron durante este episodio y refleja uno de los problemas más interesantes para el análisis de este tipo de acontecimientos: su resistencia a ser clasificados de modo taxativo. Dicho de otro modo, lo que más me interesa resaltar de esta cuestión es que al posibilitar tantas controversias y definiciones sobre las identidades de sus actores, el sentido del acontecimiento y su naturaleza espontánea u organizada, la discusión misma está dando cuenta del modo en que el propio acontecimiento y los sujetos que lo protagonizaron desbordan permanentemente las categorías más usuales del análisis político y social y se resisten a una clasificación definitiva y totalizadora, o a subsumirse a unas perspectivas conceptuales que tienden a diseccionarlos en sus partes o dimensiones componentes y preexistentes para encontrar en alguna de ellas su sentido o identidad primordial.

Este problema ha sido, en parte, identificado por autores como Altamirano (1994), Hernández (2000) y Pittaluga (2015) cuando advierten las limitaciones de los análisis que al subsumir por completo al Cordobazo 
dentro de un proceso más amplio que lo instala en una continuidad que va de sus antecedentes hacia sus consecuencias impiden visualizar, a la vez que relativizan, el impacto que el Cordobazo tuvo como experiencia, como acontecimiento que "sus protagonistas vivieron como uno de los momentos del siglo donde la historia parecía dar un viraje" (Hernández 2000), como un acontecimiento que por un momento instaló otro tiempo, un tiempo, como recuerda Altamirano "...en el que la significación del Cordobazo se mantuvo flotante y libre, en el que la brech a que habia producido en el continuo histórico siguió abierta, en que la expectativa de lo nuevo predominó por sobre lo ya pensado y lo ya visto" (Altamirano 1994). O, como lo recuerda Juan Carlos Cena, "el Cordobazo fue un catalizador. Lo que fue o existió en una situación normal, apacible para algunos, ese día que era 29, de pronto estalló en forma espectacular y todo se trastocó" (Cena, 1998).

Redireccionar la investigación hacia la identificación y el análisis de las dinámicas de confrontación que posibilitaron la convergencia de una pluralidad de actores y luchas en las calles de estas ciudades, y hacia la dimensión subjetiva de estas protestas en tanto experiencias vividas como momentos de "trastrocamiento" de la normalidad, de momento de ruptura de lo establecido, de sentidos flotantes, de "desorden" y "desborde", nos permite enunciar otra forma de filiación posible entre estos acontecimientos, más allá de los conflictos puntuales que los catalizaron y la naturaleza sociológica de los actores que los protagonizaron. Pero, sobre todo, nos permitirá restituir a estos episodios los sentidos de apertura, de ambigüedad, de incertidumbre que contenían y con los que nutrieron al proceso político de radicalización en el que se insertaron y contribuyeron a expandir. En tanto dinámica que desbordaba las expectativas y objetivos de sus protagonistas; en tanto expansión de prácticas colectivas, solidarias y horizontales que surgían de abajo hacia arriba, capaces de contener la pluralidad y a la vez de construir horizontes convergentes; en tanto expresión simultánea de rebeldía contra el autoritarismo y la dictadura, contra las injusticias económicas y sociales, contra la desarticulación de los mecanismos tradicionales de la representación y articulación de los poderes locales y que podían remitirse a diferentes tradiciones políticas, "el pueblo" emergía en estas puebladas como una potencia imprecisa que desdibujaba las identidades y las formas conocidas de la política tradicional, que desafiaba las jerarquías y roles sociales establecidos y que acotaba las supuestas distancias teóricas y prácticas entre las luchas y objetivos democráticos, corporativos o revolucionarios.

A partir de estas consideraciones preliminares, proponemos entonces pensar a estos episodios como el resultado de procesos específicos de confrontación dinámica entre actores y conflictos diversos y preexistentes (Mac Adam, Tarrow, Tilly, 2001) a la vez que como "acontecimientos", como momentos de ruptura (Altamirano 1994, Hernández 2000, Schuster 2005, Pittaluga 2015), como experiencias de rebeldía que al calor de la acción misma y de la mano de una constelación de prácticas desafiantes de la autoridad, trastrocaron el escenario habitual de la interacción social cotidiana allí donde ocurrieron.

En consecuencia, lo que proponemos es pensar y analizar estos acontecimientos desde una doble perspectiva, tanto diacrónica como sincrónica. Una mirada diacrónica nos permitirá observar la conformación de los campos de protesta y las redes de interacción social, política y cultural que se fueron consolidando a lo largo del tiempo en estas localidades, así como los sentidos que vehiculizaron, al calor de los procesos de reestructuración productiva, de desarticulación del sistema político y de radicalización que nutrieron la acumulación de demandas y conflictos puntuales que antecedieron y habilitaron los estallidos.

Sin embargo, en tanto "la conexión entre las condiciones de una acción de protesta y la acción misma es indeterminable (....) la derivación de la acción a partir de sus condiciones es radicalmente contingente" en la medida que la acción misma siempre supone "un quiebre, una ruptura con la serie de interacciones sociales que teníamos antes de ella" (Schuster 2005). Es en este sentido que proponemos también considerar a estos estallidos como acontecimientos cuya lógica y dinámica no pueden subsumirse a la identificación de las causas o procesos previos que los habilitaron. Llevar adelante un análisis también sincrónico, en consecuencia, implica reconocer que una vez que ocurren, estas rebeliones, estos estallidos, adquieren una lógica y una dinámica propia que resignifica los conflictos y sentidos preexistentes en el marco de un nuevo escenario de confrontación que, en gran medida, escapa al control y a los objetivos específicos de los actores que los 
desencadenaron, a la vez que habilita y potencia formas alternativas de interacción social no necesariamente previstas en sus antecedentes. En esta dirección, lo que proponemos es desnaturalizar la irrupción "del pueblo" y darle sentido como acontecimiento en sí mismo, como momento de ruptura, como emergencia expresiva e imprevisible de otras formas posibles de interacción social y subjetivación política (Adamovsky 2011, Pittaluga 2015, Vommaro 2013, Pereyra 2013); "como momento en que los sujetos se comportan de modo impropio y toman la palabra bajo otro nombre" que implica una pérdida de identidad, al menos parcial, con el rol social prefigurado por el orden que se cuestiona (Ranciere 2011).

Desde esta perspectiva, la potencia política que expresaron estos estallidos estaría dada por la aparición de estos "pueblos rebeldes", cruzados por múltiples tensiones e identidades preexistentes, y por ello también desnaturalizados y polifónicos que, a modo de hipótesis, no son otra cosa que la protesta misma; una rebelión, una potencia nueva que irrumpe, y por lo tanto interrumpe el devenir del tiempo lineal y homogéneo y abre el proceso político a un tiempo distinto, a un tiempo "ahora", a un tiempo "mesiánico" como diría Benjamin (1991) en el que la acción misma configura otras formas posibles de interacción social. Dicho de otro modo, el pueblo que irrumpe en la escena con estos episodios, no sería sólo ni principalmente representativo de intereses objetivos o identidades y demandas preexistentes articuladas coyuntural e instrumentalmente en la lucha antidictatorial sino, sobre todo, expresivo de una potencia que podemos denominar antagonista (Pittaluga 2015) por su capacidad de producir dislocaciones y desplazamientos en las jerarquías y las normas de interacción política y social que regían en estos territorios (Cavarozzi, 1986). Una potencia siempre latente, arraigada en la fisura constitutiva de la política moderna que separa al "Pueblo", con mayúscula, como principio abstracto de la soberanía, y al "pueblo" o a los "pueblos", concretos y con minúscula, excluidos o marginados del poder (Agamben 2001). Una potencia liberada y reactualizada en sus múltiples significados y posibles direcciones por la interacción política y social activada al calor de las oposiciones sectoriales pero convergentes contra la dictadura de la Revolución Argentina. Una potencia devenida "pueblos rebeldes" posibles fulguraciones de sutura-, en la dinámica específica que tomó la lucha de calles en algunas ciudades del interior de nuestro país.

Pensar las puebladas como una potencia antagonista que se reactualizó en la dinámica específica que tomó la lucha de calles en algunas ciudades de nuestro país en aquellos años, nos permite recuperar, aunque desde otro lugar, la pregunta por la relación entre los procesos de movilización y acción colectiva de protesta articulados alrededor de clivajes no clasistas y la articulación clasista de la totalidad social. Una cuestión compleja y de central importancia para cualquier perspectiva crítica preocupada por comprender y visibilizar las dinámicas de poder y resistencia que caracterizan a las sociedad contemporánea, y que ya está presentes en las reflexiones tempranas de Antonio Gramsci sobre los problemas de construcción de hegemonía, en los aportes provenientes de la escuela de Frankfurt, del marxismo británico, del marxismo analítico y, más recientemente, de la teoría feminista y de los estudios subalternos (Adamovsky, 2007). Estas reflexiones convergen en torno a la necesidad de explorar los microfundamentos y entramados complejos de sentido que habitan los conflictos y acciones colectivas que sin dejar de estar atravesados por la lucha de clases sin embargo también suelen estar permeados "por el sentido común dominante y aparecer en formas y actores cambiantes, como los que las teorizaciones sobre los movimientos sociales y la acción colectiva intentan aprehender" (Viguera 2009). Estas perspectivas, en consecuencia, permiten pensar la dominación de clase como un proceso mucho más amplio y multifacético a partir del cual la lente de la lucha de clases puede remitir a las múltiples formas en que se procesa y se expresa el complejo entramado de dominación/ resistencia, hegemonía/contrahegemonía, producción/disrupción implicados en el capitalismo entendido como un "régimen social" (Castoriadis, 2013) que excede su dimensión puramente económica e involucran en la dominación de clase "no sólo a quienes trabajan en la producción de mercancías en un sentido estricto, sino también a todos los que indirectamente la hacen posible y, en general, a todos aquellos cuyas vidas están sujetas a las normas de producción y reproducción que impone el capitalismo" (Adamovsky, 2007) 
Desde estas miradas renovadoras es posible abandonar la imagen reificada de "la clase obrera" como el sujeto preferencial que encarna el antagonismo social y visualizar también como parte del proceso de dominación capitalista, entre otras dimensiones, los mecanismos de clasificación, de ordenamiento de las diferencias, en virtud de los cuales se construyen normas de interacción social y jerarquías de poder a partir de criterios no necesariamente clasistas pero sobre los cuales también se apoya el dominio de clases. Por ello mismo, como lo advierte John Holloway, "la lucha de clases también es la lucha por clasificar y contra ser clasificado al mismo tiempo que una lucha entre clases constituidas (...) es un incesante antagonismo entre la sujeción de la práctica a las formas fetichizadas, pervertidas, definidoras del capitalismo y el intento de vivir contra -y más allá- de estas formas (...) no luchamos como clase trabajadora, luchamos en contra de ser clase trabajadora, en contra de ser clasificados" (Holloway, 2004)

En definitiva, pensar a las "puebladas" como resultado de procesos de confrontación dinámicos y a la vez como emergencia de una potencia antagonista capaz de producir dislocaciones en las normas de interacción social y en las identidades y roles sociales preexistentes, nos permite reinscribirlas, desde otro lugar, en el entramado complejo y cambiante de las formas histórico concretas con las que los "malestares de la sociedad" alimentaron al conflicto social y a la lucha de clases en nuestro país durante aquellos años. Nos permite, en consecuencia, recuperar a esos procesos de confrontación y a esas experiencias de rebeldía compartida por tantos y tan diversos sectores como expresivas de las múltiples grietas abierta

\section{ReFERENCIAS}

Acha, Omar (2010), "Dilemas de una violentología argentina: tiempos generacionales e ideologías en el debate sobre la historia reciente", ponencia presentada en las V Jornadas de Trabajo sobre Historia Reciente, Universidad Nacional de General Sarmiento, 22 al 25 de junio de 2010, accesible en http://eltopoblindado.com

Adamovsky, Ezequiel (2007), "Historia y lucha de clases: repensando el antagonismo social en la interpretación del pasado (y de vuelta sobre un debate ausente en la historiografía argentina)”, Nuevo Topo, N 4, Bs. As., septiembreoctubre.

Adamovsky, Ezequiel (2011), "Por qué estudiar la revolución Rusa”, en Cernadas, J y Lvovich, D, Historia ¿para qué? Revisitas a una vieja pregunta, Prometeo-UNGS, Bas. As.

Adamovsky, Ezequiel et al (2007), “Tiempo de insurgencia: experiencias comunistas en la Revolución Rusa”, accesible en http://www.rebelion.org/docs/57669.pdf

Agamben, Giorgio (2001), “¿Qué es el pueblo?” en Medios sin fin. Notas sobre la política, Pretexto, Valencia

Altamirano, Brennan, James, Gordillo, Torre, y otros (1994) “Dossier: El Cordobazo, la Universidad, la Memoria"; en Estudios, n ${ }^{\circ}$, Revista del Centro de Estudios Avanzados de la UNC, Córdoba.

Alvarez, Gustavo (2006), “El catamarqueñazo: protesta y rebelión civil en la Catamarca de los 70”, ponencia presentada en las Jornadas Internacionales de Historiografía Regional, Resistencia, Chaco, 9 y 10 de noviembre de 2006

Antognazzi, Irma y Ferrer, Rosa (Comp.) (1995), Del Rosariazo a la democracia del 83, Escuela de Historia, Facultad de Humanidades y Artes de la Universidad Nacional de Rosario,

Arruti, Mariana (2004), Trelew. La fuga que fue masacre

Aufgang Lidia y Balvé Beba (1989), Las puebladas, dos casos de protesta social. Cipoletti y Casilda, Bs As., CEAL

Auzoberría, Miguel (2007), Los '70 y la crisis politica en Santa Cruz: la caida del Comodoro Raynelli, Dunken, Bs. As.

Balvé, Beba et. Al (1973), Lucha de calles, lucha de clases, Bs As., La Rosa Blindada

Balvé, Beba y Balvé, Beatriz (1989), El 69; huelga politica de masas. Rosariazo/ Cordobazo/ Rosariazo. Bs As., Contrapunto

Bassi, Paula y Pauli, Diego (2003), Prohibido Dormir, Buenos Aires

Benjamin, Walter (1991), Para una crítica de la violencia y otros ensayos. Iluminaciones $I V$, Taurus Humanidades, Madrid 
Bonavena, Pablo et al (1998), Orígenes y desarrollo de la guerra civil en la Argentina, 1966-1976. Buenos Aires, Eudeba Brennan James (1996), El Cordobazo. Las guerras obreras en Córdoba, Bs As, Sudamericana

Castillo, F. (2007) "El jujeñazo. Las dimensiones discursivas y espaciales de una protesta en San Salvador de Jujuy en 1971", Ponencia presentada en las XI Jornadas Nacionales de Investigación en Comunicación; Universidad Nacional de Cuyo, Mendoza.

Castoriadis, Cornelius (2013), La institución imaginaria de la sociedad, Tusquets, Barcelona

Cavarozzi, Marcelo (1983), Autoritarismo y Democracia, 1955-1996, CEAL

Cena, Juan Carlos (2000), El Cordobazo, una rebelión popular, La Rosa Blindada, BA, Colección de ensayos Emilio Jáuregui.

Cheren, Liliana (1997), La Masacre de Trelew, 22 de agosto de 1972. Institucionalización del Terrorismo de estado, Corregidor, Bs. As

Colectivo Famntoma, El mendozazo... herramientas de rebeldia, editorial EDIUNC, Mendoza, 2012

Crenzel, Emilio (1991), El Tucumanazo (1969-1974). Buenos Aires: Centro Editor de América Latina.

De Riz, Liliana. La política en suspenso 1966/1976. Bs. As., Paidós, 2000

Delich Francisco (1974), Crisis y protesta social: Córdoba, mayo de 1969, Bs As., Siglo XXI,

Favaro,O., Zapata,Y. y Araya, L. (2011),"Tierra de todos o de nadie". Las puebladas del alto valle deRío Negro, en el contexto de las protestas de los años 1960 -1970, Iberoamericana global. The Faculty of Humanities. The Hebrew University of Jerusalem, $\mathrm{Vol} 4$, No 1

Flores, Gregorio (1994), Sitrac-Sitram. Del Cordobazo al clasismo., Ediciones Magenta, Bs.As

Fradkin, Raúl (2001), "Poder y conflicto social en el mundo rural: notas sobre las posibilidades de la Historia Regional", en Sandra Fernandez y Gabriela Dalla Corte (comps.), Lugares para la Historia. Espacio, historia regional e historia local en los estudios contemporáneos, UNR, Rosario

Gonzalez Bombal, Inés (1988), Los Vecinazos. Las protestas barriales en el Gran Buenos Aires, 1982-83, Ediciones del IDES; Bs. As.

Gordillo, Mónica (1996), Córdoba en los '60. La experiencia del sindicalismo combativo, Córdoba, UNC

Gordillo, Mónica (2001), Actores, prácticas, discursos en la Córdoba combativa: una aproximación a la cultura politica de los 70. Córdoba: Ferreyra Editor, 2001.

Halperin, T. (1994), La larga agonia de la Argentina peronista, Ariel.

Hernadez, Juan (2000), “El Cordobazo y sus interpretaciones”, El Rodaballo, año VI, No10

Hilb, C. y Lutzky, D. (1986). La nueva izquierda argentina: 1960-1980. Política y violencia, Bs As: CEAL.

Holloway John (2004.), Clase=Lucha: antagonismo social y marxismo critico, Herramientas, Bs. As

Kotler, Rubén (2000), “El Tucumanazo, los Tucumanazos, 1969-1972. Memorias enfrentads: entre lo colectivo y los individual", ponencia presentada en las XI Jornadas Interescuelas/Departamentos de Historia, Tucumán

Kotler, Rubén (2009), El tucumanazo. Un documental necesario, documental fílmico, Cine Independiente Producciones, Tucumán

Kotler, Rubén, "La alianza obrero estudiantil como respuesta a la dictadura de 1966 en la periferia argentina. El caso de Tucumán”,Clio-Revista de pesquisa histórica, No31,UFPR, Brasil, accesible en http://www.revista.ufpe.br/re vistaclio/index.php/revista/article/viewFile/360/197

Laclau, Ernesto (2005), La razón populista, FCE, Bs. As.

Martínez, Tomás Eloy (1997), La Pasión según Trelew, Planeta, Bs.As,

Mc Adam, Tarrow, Tilly (2001), Dynamics of Contention, Cambridge University Press

Nassif, Silvia.(2012) Tucumanazos. Una huella histórica de las luchas populares 1969-1972, Instituto de Investigaciones Históricas “Dr. Ramón Leoni Pinto", Fac. Filosofía y Letras. UNT, Tucumán

Ollier, María M (1986)., El fenómeno insurreccional y la cultura politica (1969-1973), Bs As, CEAL, 1986. 
Pereyra, Sebastián (2013), "El 2001 como acontecimiento y como proceso. Desetructuración social y crítica de la política”, en Pereyra, Vommar y Pérez (comp), La grieta. Política, economia y cultura después del 2001, Bs. As., Biblos

Pérez, Néstor y Viano, Cristina (1994) “El 69: del mayo rosarino al rosariazo", en Barrotarán, Patricia y Pozzi, Pablo, Estudios inconformistas sobre la clase obrera argentina, 1955-1989, Letra Buena, Bs. As.

Pittaluga, Roberto (2015), "La inteligencia obrera", ponencia presentada en las XV Jornadas Interescuelas/ Departamentos de Historia, Comodoro Rivadavia, septiembre 2015

Ramírez, Ana Julia (2001) “Las puebladas en la Argentina de los'70. El Caso de General Roca, julio de 1972”, ponencia presentada en el Congreso de la Asociación Latinoamericana de Estudios Sociales (LASA 2001), Washington D.C, EEUU.

Ramírez, Ana Julia (2007), "Las mediaciones locales de la protesta. El caso del Trelewazo (octubre de 1972)", en Sociobistórica, No 19 /20, Prometeo, Bs.As.

Ramírez, Ana Julia y Viguera, Aníbal (2006), "La protestation sociale dans les trois dernières décennies du XXe. Siècle", en Revista Matériaux pour l' histoire de notre temps, Bibliothèque de Documentation Internationale Contemporaine, Université de Nanterre, Francia, No 81 (ISSN 0769 - 3206), enero-marzo

Ramírez, Ana Julia, “Tucumán 1965-1969: movimiento azucarero y radicalización política” en Mundo Nuevo, Nuevos Mundos, Débats, mis en ligne le 12 juillet 2008, http://journals.openedition.org/nuevomundo/38892

Romero, Luis Alberto(2000) "La violencia en la historia argentina reciente; un estado de la cuestión, en PérotinDumon, Anne, ed Historizar el pasado vivo en América Latina, 2000.

Schuster, Francisco (2005), "La protesta social y el estudio de la acción colectiva", en Naishtat, F., Schuster, F., Nardacchione G. et al. (Comp.) Tomar la palabra. Estudios sobre protesta social y acción colectiva en la Argentina contemporánea. Buenos Aires, Prometeo.

Scodeller, Gabriela (2006), "Conflictos gremiales en la historia reciente argentina. Una mirada”, Revista A Contra Corriente, Vol. 6, № 3

Tarcus, Horacio (1999), “Un mayo caliente: el Cordobazo”.Todo es Historia № 382

Torre, Juan Carlos, "Dossier: El Cordobazo, la Universidad, la Memoria";Estudios, n ${ }^{\circ}$, Revista del Centro de Estudios Avanzados de la UNC, Córdoba

Tortti Cristina (1999), "Protesta social y Nueva Izquierda durante el Gran Acuerdo Nacional"; en La primacía de la politica, Pucciarelli, A., Ed. EUDEBA, BS As

Tortti, Cristina.(2002) “Izquierda Y Nueva Izquierda En La Historia Reciente De La Argentina, Primer Coloquio "Historia y Memoria" Facultad de Humanidades- UNLP, 18-20 abril

Tosco, Agustín (1989), Escritos y discursos, BA, Contrapunto.

Viguera, Anibal (2009), "Movimientos sociales y lucha de clases", en Conflicto Social, Año 2, N 1, Instituto de Investigciones Gino Germani, UBA

Vommaro, Gabriel (2013), “¿Cuándo, dónde, quiénes? Tres preguntas para volver a pensar los sentidos políticos del 2001, en Pereyra, Vommar y Pérez (comp), La grieta. Politica, economía y cultura después del 2001, Bs. As., Biblos

Western, W, Fernández Pícolo, M y De Oto,A:J;(1991) "El Movimiento Social por los Derechos Humanos en Trelew, 1969-1973", Facultad de Humanidades y Ciencias Sociales, Consejo de Investigaciones de la Universidad Nacional de la Patagonia, Trelew

Yappert, Susana y Bohoslavsky (2012), Ernesto, Elegantes y rebeldes. El rocazo de 1972, Fondo Editorial Municipal, General Roca.

\section{Notas}

1 Me refiero en este caso a los estallidos ocurridos en Córdoba, Tucumán, Rosario, Santa Fe, Corrientes y Cipolletti, durante 1969; en Tucumán, Salta, y Catamarca en 1970; en Casilda, Jujuy, Río Gallegos y Córdoba de nuevo en 1971 y en Mendoza, Rawson, Malargue, Trelew, General Roca y Tucumán nuevamente en 1972. 
2 Más allá de la destitución de autoridades locales como intendentes, autoridades universitarias o policiales, en 6 de estos casos tuvieron que renunciar los respectivos gobernadores (Mendoza, Tucumán, Córdoba, Catamarca, Río Gallegos y. General Roca). Por su parte, es bien sabido que luego del Cordobazo fue desplazado el Ministro de Economía de la Nación, Krieger Vasena, y que los dos Cordobazos fueron acontecimientos centrales en el desplazamiento, aunque no inmediato, del Presidente Onganía en 1970 y del Presidente Levingston en 1971 respectivamente.

3 Los abogados que convocaron a dicha conferencia eran José María Martinelli, Carlos M. Zamorano, y Ricardo Ripodas. En particular hicieron alusión a las torturas a las que habrían sido sometidos Juan Manuel Carrizo, Ramona Márquez de Alderete, Alberto Herranz, Osvaldo Garibaldi y Gloria Susana Machado, todos acusados de participar en el ERP y los dos últimos mencionados también estudiantes de la UNT. Ver La Gaceta, 25/6/72 junio, pag 11

4 La Gaceta, 25/6/72, pag 6

5 ibid

6 La Gaceta, 26/6/72, pag 7

7 La Gaceta, 25/6/72-6, pag 7

8 La Gaceta 26/6/72-6 pag 6.

9 La Gaceta 27/6/72-pag 7

10 Los listados de detenidos pueden leerse en el diario La Gaceta que, según su propia información, los publicaba tal cual se los entregaban las autoridades militares. En la mayoría de los casos junto a los nombres también se señala la edad de los detenidos: más del $95 \%$ tenían entre 18 y 24 años.

11 Parte $\mathrm{N}^{\circ} 1446$, con fecha 26/6/72, procedente de Seguridad Federal, SIDE, Archivo DIPBA, Mesa Referencia, Legajo R15838.

12 Esta pueblada fue reconstruida por Lidia. Aufgang (1989).

13 Diario Rio Negro, 10/7/72, pág.. 13.

14 Ibid.

15 Hecho conocido como "la masacre del Trelew"

16 En la reunión estuvieron presentes dirigentes del MID, del PJ, de la UCR, del PDC, del Partido Autonomista del Chubut, y del PSP de Trelew y Rawson. Ver Jornada y El Chubut, 13 y 14-10-72

17 Aparte de los partidos políticos que la convocaron, entre las muchas organizaciones que apoyaron y participaron de la primera Asamblea del Pueblo realizada el 11/10/72 estaban: SOYEAP, Sindicato de Trabajadores Viales del Chubut, Estudiantes del Colegio Nacional de Trelew y de la Escuela Nacional de Comercio, Centro de Martilleros, Empleados Bancarios, diario El Chubut, Juventud Peronista, Profesores y Personal Administrativo del Instituto Universitario de Trelew, Asociación de Sanitarios del Valle del Chubut, Circulo de periodistas, Movimiento Textil Chubutense, Colegio de Abogados, Colegio de Escribanos, Teatro Nuevo Grupo, Teatro El Grillo, ENA, Frente de Juventudes Políticas, Juventud del Partido Socialista Popular, Centro de Arquitectos, Ingenieros, Geólogos y Agrimensores del Noreste del Chubut, Asociación Médica del Chubut, UOCRA, Cine Club "Platea 3", Barrio de Ayuda Mutua de Rawson, Barrio Alsúa de Rawson, Juventud Peronista de Rawson, Asociación de Taxis Trelew, Cámara de Industria y Comercio de Pto. Madryn, Cámara de la Construcción de Rawson, Cámara de Industria y Comercio de Esquel, CGT de Comodoro Rivadavia, Obreras de la fabrica ROMA, UOM seccionales Trelew y Rawson, Carniceros Unidos del Valle del Chubut. Ver diarios El Chubut y Jornada de los días 13 y 14/10/1972

$18 \mathrm{El} \mathrm{Dr}$. Amaya, había sido arrestado por fuerzas militares el día 18 de agosto, acusado de presunta vinculación con la fuga de los presos del penal de Rawson, por encontrarse presente en el aeropuerto local el día de la misma.

19 La CSPP sacó su primer comunicado público el 22/9/1971. Ver Diario Jornada, 23/9/71, pag. 4.

20 La flexibilización de la disciplina en el penal era uno de los objetivos buscados por los presos y esta red solidaria. La dinámica interacción entre la cárcel y la sociedad local hizo más fácil el intercambio de información entre el adentro y el afuera y, por lo tanto, coordinar y facilitar las posibilidades de fuga. Para un relato detallado de cómo la entrada permanente de los apoderados de la ciudad de Trelew y Rawson a la U6 ayudó a la flexibilización de la disciplina del penal y, en consecuencia, a la planificación de la fuga, ver Liliana Cheren, La Masacre de Trelew, 22 de agosto de 1972. Institucionalización del Terrorismo de estado, Corregidor, Bs. As, 1997

21 Todos estos conflictos fueron analizados con mayor profundidad en Ana Julia Ramírez, "Las mediaciones locales de la protesta: el caso del Trelewazo”, Socio-histórica. Cuadernos del CISH, N 18/19, Prometeo/UNLP, 2008

22 Martínez, Tomás Eloy op. cit. pag. 37

23 Estas definiciones son algunas de las tantas las que recorren la vasta producción escrita sobre el Cordobazo y que hemos seleccionado solamente a modo de ejemplo para graficar el problema que nos interesa plantear. Para una lectura más pormenorizada de este acontecimiento y sus interpretaciones remitirse a la bibliografía 